\title{
A quantitative estimate of the function of soft-bottom sheltered coastal areas as essential flatfish nursery habitat
}

\author{
E. Trimoreau ${ }^{a}$, B. Archambault ${ }^{a}$, A. Brind'Amour ${ }^{b}$, M. Lepage ${ }^{c}$, J. Guitton ${ }^{a}$, O. Le Pape ${ }^{a, *}$
}

\author{
${ }^{a}$ AGROCAMPUS OUEST, UMR985 ESE Ecologie et santé des écosystèmes, F-35042 Rennes, France \\ b Ifremer, Centre de Nantes, Rue de l'Île d'Yeu, B.P. 21105, 44311 Nantes, France \\ c Irstea, Unité Ecosystèmes Estuariens et Poissons Migrateurs Amphihalins, 50, Avenue de Verdun Gazinet, \\ 33612 Cestas cedex, France
}

*: Corresponding author : Olivier Le Pape, email address : Olivier.Le.Pape@agrocampus-ouest.fr

\begin{abstract}
:
Essential fish habitat suitability (EFHS) models and geographic information system (GIS) were combined to describe nursery habitats for three flatfish species (Solea solea, Pleuronectes platessa, Dicologlossa cuneata) in the Bay of Biscay (Western Europe), using physical parameters known or suspected to influence juvenile flatfish spatial distribution and density (i.e. bathymetry, sediment, estuarine influence and wave exposure). The effects of habitat features on juvenile distribution were first calculated from EFHS models, used to identify the habitats in which juvenile are concentrated. The EFHS model for S. solea confirmed previous findings regarding its preference for shallow soft bottom areas and provided new insights relating to the significant effect of wave exposure on nursery habitat suitability. The two other models extended these conclusions with some discrepancies among species related to their respective niches. Using a GIS, quantitative density maps were produced from EFHS models predictions. The respective areas of the different habitats were determined and their relative contributions (density $\times$ area) to the total amount of juveniles were calculated at the scale of stock management, in the Bay of Biscay. Shallow and muddy areas contributed to $70 \%$ of total juvenile relative abundance whereas only representing $16 \%$ of the coastal area, suggesting that they should be considered as essential habitats for these three flatfish species. For S. solea and $P$. platessa, wave exposure explained the propensity for sheltered areas, where concentration of juveniles was higher. Distribution maps of $P$. platessa and $D$. cuneata juveniles also revealed opposite spatial and temporal trends which were explained by the respective biogeographical distributions of these two species, close to their southern and northern limit respectively, and by their responses to hydroclimatic trends.
\end{abstract}

Keywords: coastal and estuarine dependent species ; nursery ground ; habitat suitability models ; Geographic Information System ; Bay of Biscay 


\section{Introduction}

Coastal and estuarine nursery habitats are essential for many marine fish species (Peterson et al., 2000, Beck et al., 2001 and Fulford et al., 2011), particularly for flatfish (Miller et al., 1984 and Able, 2005). The suitability of these habitats influences juvenile growth and survival rates (Rijnsdorp et al., 1992 and Gibson, 1994) and can act as habitat bottlenecks (lles and Beverton, 2000). As a consequence, the vulnerability of coastal habitats to anthropogenic stressors (Franca et al., 2012, Halpern et al., 2007 and Halpern et al., 2008) can alter recruitment and future population renewal. Relationships between species and their habitats are a central issue to characterize the mechanisms determining habitat suitability. However, there is a lack of quantitative evidence of the importance of habitat suitability in patterns driving population dynamics. Despite the high number of studies which have focused on coastal habitat use by fish species, the value of habitats for fish population dynamics seldom remains quantified (Levin and Stunz, 2005 and Fodrie et al., 2009). One required approach to bridge this gap from knowledge to quantitative estimates of EFHS consists of predicting geographic distributions of populations at different life stages, and especially for juveniles on nursery grounds, through habitat mapping (Rubec et al., 1999 and Lauria et al., 2011). EFHS maps could constitute essential elements for prioritizing areas for conducting spatial ecosystem assessments (Brown et al., 2000 and Cogan et al., 2009). They may solve questions about what constitutes high-value fish habitat for exploited species (Fodrie and Mendoza, 2006) and provide information needed for conservation purpose 
(Stoner, 2003). The identification and mapping of essential fish habitats, especially nursery grounds,

may also help to prioritize management measures. Especially, such maps would be appropriate for Marine Protected Areas design, to insure that they are efficient in maintaining the potential of marine living resources renewal.

The Bay of Biscay, an arm of the North Atlantic indenting the west coast of France (ICES Division Area VIIIa/b; Fig. 1), is considered to be a stock management unit for many exploited marine fish species (Anon., 2011). The inshore waters of the Bay of Biscay support nursery areas for several commercially important species, notably flatfishes (Hermant et al., 2010). Estuaries and coastal areas have been studied for several decades in the Bay of Biscay and a large amount of scientific data on fish abundance is available (Brind'Amour and Lobry. 2009). For S. solea, Le Pape et al. (2003b) provided maps of density index over the Bay of Biscay and identified essential habitats. To follow up this first approach, the present studies aimed at achieving two objectives:

- The previous quantitative description of habitat suitability for the $S$. solea population of the Bay of Biscay was conducted to develop an early quantitative assessment of its nursery habitats using bathymetry, sediment structure and estuarine influence. EFHS model has been used to identify the habitats in which juvenile $S$. solea were concentrated. Similar approaches on juvenile S. solea were previously developed in the Eastern Channel (Riou et al., 2001; Eastwood et al., 2003; Rochette et al., 2010) and along the Portuguese coasts (Vasconcelos et al., 2010) with the same conclusions about the interest of shallow soft bottom areas inside or near estuarine influence. However, all these EFHS model based on the distribution of young of the year (0-group) $S$. solea led to a high non explained variability (e.g., in the Bay of Biscay: > 70\% for model including both descriptors of habitat features and mesoscale variability among geographical sectors but close to $90 \%$ when only habitat descriptors were used; Le Pape et al., 2003b). The first objective of the present study was to improve the EFHS model for juvenile $S$. solea. Several studies have shown that coastal exposure affects habitat structure and juveniles of most flatfish species prefer sheltered parts of the coast and embayments (Howell et al., 1999). However, few studies have quantified the impact of coastal exposure (Pihl and van der Veer, 1992) and integrated its effect in EFHS mapping (Maxwell et al, 2009; for adult fish including $S$. 
solea). Indicators for wave exposure of the coastal areas were thus used to improve the description of nursery habitat suitability (Fodrie and Mendoza, 2006) in the Bay of Biscay.

- S. solea was the single studied species in previous juvenile fish habitat mapping approaches in the Bay of Biscay. Thus there is a need to assess the impact of the habitat descriptors and potentially extend the mapping procedure to other estuarine and coastal dependent flatfish species. The two other most common estuarine and coastal dependent flatfish species during the last three decades $(P$. platessa, D. cuneata; Désaunay et al., 2006; Hermant et al., 2010) were selected in addition to $S$. solea, both being of interest for fisheries. $P$. platessa has a life history similar to $S$. solea, characterized by winter offshore spawning areas, post-larvae settling on inshore nursery grounds during spring and juveniles growing within nursery areas until they mature to adult age and move to the continental shelf (Koutsikopoulos et al., 1991, Hermant et al., 2010). The coastal nursery dependence of D. cuneata is similar but this species is a summer spawner (Hermant et al., 2010). The juvenile distribution patterns of juvenile $P$. platessa has been investigated from habitat suitability models and/or quantitative mapping procedure in numerous other areas in Western Europe, the Baltic (Pihl et al., 2000; Wennhage et al., 2007), the North Sea (van der Veer et al., 2011) and the Eastern Channel (Riou et al., 2001). These studies described P. platessa's preference for shallow soft bottom areas and pointed out the interest to include coastal exposure as descriptor of habitat suitability. On the contrary, knowledge on D. cuneata is scarce, without any existing quantitative estimate of habitat suitability.

The analysis is based on 0-group of these three species on which data have been gathered from surveys conducted over a 30-year period throughout the estuarine and coastal areas of the Bay of Biscay. Achievement of the two objectives relies on quantitative mapping based on the relation between 0-group flatfish densities and habitat descriptors to identify nursery habitats of major importance. EFHS models were developed from generalized linear models to describe habitat related patterns in flatfish juvenile distribution. Then, these models outputs and Geographic Information System (GIS) were combined to provide quantitative habitat maps and relative contributions of the different habitats to the total proportion of juvenile flatfish at the scale of the Bay of Biscay population, while accounting for interannual variability. 


\section{Material and Methods}

\subsection{Fish survey data}

The study area

The Bay of Biscay study area (Fig.1) includes six major nurseries (Le Pape et al., 2003b) which have been considered as independent sectors due to the coastal morphology: Vilaine, Loire and Gironde, three estuaries, and Bourgneuf, Pertuis Breton and Pertuis d'Antioche, three bays. Other coastal sectors of the Bay of Biscay were considered as unsuitable nursery areas from previous approaches (Le Pape et al., 2003b) and were not included in the analysis. As the 6 considered sectors constitute almost the entire area of repartition at the scale of the Bay of Biscay for the juveniles of the three considered species, extrapolation at the scale of the management unit (Bay of Biscay) can be performed. As this study focuses on marine species, the study area was restricted to the upstream limit of the oligohaline zone (i.e. higher than 5PSS, the limit of marine species extent; Courrat et al., 2009; Nicolas et al., 2010; Rochette et al., 2010) within rivers. The off-shore limit was set at the $35 \mathrm{~m}$ isobath, as juveniles of flatfish species are scarcely present in deeper waters (Riou et al., 2001). Scientific trawl surveys data in the coastal areas of the Bay of Biscay

Data from beam trawl surveys focusing on marine juveniles fish, conducted on soft bottoms throughout the coastal areas of Bay of Biscay from the 1980s up to present by three different scientific institutes have been gathered. The six aforementioned nurseries have been repeatedly sampled over this period (Table 1). Most of these surveys were conducted from late summer to mid-autumn; a period considered as appropriate to study flatfish nursery grounds (i.e. relatively stable density and distribution pattern of juvenile flatfish which are representative of the nursery function during the productive period; Dorel et al., 1991; Courrat et al., 2009). Only trawl hauls performed between the end of August and mid-October were selected for the study; they originated from three different sources (Table 1): 
- IFREMER (France). Data used in this study originated from the same surveys series as the ones used by Le Pape et al. (2003b). These series were upgraded with the surveys conducted from 2000 to 2010 (Brind'Amour and Lobry, 2009; Hermant et al; 2010 and further) in the six studied nursery sectors with the same sampling protocol $(+35 \%$ of trawl hauls from recent IFREMER survey series compared to Le Pape et al., 2003b),

- IRSTEA (France). French estuaries were investigated (Courrat et al., 2009) in the context of the European Water Framework Directive (WFD). These new surveys provided additional data in the inner part of the Gironde, Loire and Vilaine estuaries (Courrat et al., 2009; Delpech et al., 2010),

- BIO-LITTORAL (France), a scientific consultancy operated an additional survey in 2008 in the Loire estuary, following the same procedure than IRSTEA.

In all of these surveys, the gear used was a 3-m wide beam trawl with a $20-\mathrm{mm}$ stretched mesh in the cod end. Hauls were made only in daylight and performed at an average speed of 2.5 knots, ranging from 1.5 to 3 knots, for 10 to $20 \mathrm{~min}$. Further details about the sampling protocol can be found in Brind'Amour and Lobry (2009) and Delpech et al. (2010). 1643 trawl hauls (Table 1) showing no sign of tearing nor clogging were retained.

All flatfish caught were identified at the species level, counted and measured. As the aim of this study was to assess nursery habitats, the catches of 0-group were selected. This selection was done using a maximal length at age 0 for each species $(15,18$ and $11 \mathrm{~cm}$ for $S$. solea, P. platessa and $D$. cuneata respectively; Hermant et al., 2010).

\section{Correcting the data: use of a selectivity factor}

The density indices, in number of fish from 0-group, were first calculated for each 1-cm size class on each trawl haul from the selected data. As smaller fishes are subject to gear escapement, a correction function, depending on both gear and species parameters was used to reevaluate the catch for each size class of each species. The recalculated amount of juveniles at length $L$ for the species $s$, in the trawl haul $t, \mathrm{~N}_{\mathrm{est}, \mathrm{s}, \mathrm{t}}(\mathrm{L})$, is given in Eq.(1):

$$
N_{e s t, s, t}(L)=\frac{N_{\text {caught }, s, t}(L)}{S_{S}(L)}
$$


where $\mathrm{N}_{\text {caught,s,t }}(\mathrm{L})$ is the amount of catch of juveniles of length $L$ for the species $s$ in the trawl haul $t$, and $S_{S}(L)$ is the corrected proportion of juveniles of length $L$ and species $s$ selected by a beam trawl with a $20 \mathrm{~mm}$ mesh size (i.e. coefficient of selectivity). The calculation (Eq.(2)) of $S_{S}(L)$ is based on Dardignac and de Verdelhan (1978) adapted from Rochette et al. (2010):

$$
S_{S}(L)=\frac{\exp \left[\left(\frac{2 \times L_{S} 50_{M} \times \log 3}{\Delta_{M, S}}\right) \times\left(\frac{L}{L_{S} 50_{M}}-1\right)\right]}{1+\exp \left[\left(\frac{2 \times L_{S} 50_{M} \times \log 3}{\Delta_{M, S}}\right) \times\left(\frac{L}{L_{S} 50_{M}}-1\right)\right]}
$$

where $L$ is the length, in $\mathrm{mm}, L_{S} 50_{M}=\alpha_{S} \cdot M$ the $50 \%$ retention length, where $\mathrm{M}$ is the stretched mesh size in $\mathrm{mm}$ (here 20 ), and $\Delta_{M, S}=\beta \cdot L_{S} 50_{M}$ the selectivity range, i.e. the difference between $75 \%$ and $25 \%$ retentions lengths. According to the similar shape of the two species, the $\alpha_{S}$ parameter of $S$. solea (3.3; Rochette et al., 2010) has been used for D. cuneata, another value being used for $P$. platessa (2.3; Anon., 1998). $\beta$ parameter is considered common for all species $(0.385$, Rochette et al., 2010).

0-group density indices were calculated for the three species on each trawl haul accounting for the size structure of the catches by summing the recalculated catch divided by the sampled surface (Eq.(3)):

$$
\text { Density indice }_{s, t}=\frac{\sum_{L} N_{E s t, s, t}(L)}{\text { Surface }_{t}}
$$

As the catchability of these species by the beam trawl is unknown, density indices of 0-group juveniles for the three studied flatfish provided only relative information, sufficient to estimate standardized habitat related patterns but not to calculate the real overall abundance of juvenile fish present in the trawled area.

\subsection{Information on physical descriptors}

Data on physical parameters known or suspected to influence the repartition of coastal and estuarine nursery dependent species at the local stage, i.e. bathymetry, sediment, estuarine plume and wave exposure, were collected over the study area (Table 1): 


\section{Bathymetry}

A raster map of bathymetry was available as continuous numerical values. Bathymetry data have been cut into 4 classes: ] $-36 \mathrm{~m} ;-20 \mathrm{~m}]$, ] $-20 \mathrm{~m} ;-10 \mathrm{~m}]$, ] $-10 \mathrm{~m} ;-5 \mathrm{~m}$ ] and $>-5 \mathrm{~m}$ up to the coastline.

\section{Sediment structure}

A sediment structure map was created as a combination of two sources. A sediment map of the Bay of Biscay was the main source of information. Five classes of sediments were available: mud, fine sand, coarse sand, gravels, and rocks. Gravel and coarse sand have been pooled and rocky areas were excluded, as they do not host the considered flatfish species. Additional information on sediment from the inner Loire estuary was merged to this map to cover the trawl survey area. Salinity

Salinity is included in habitat suitability models to describe the positive influence of winterspring estuarine plumes and their interannual variations on flatfish habitat (Le Pape et al., 2003ab; Kostecki et al., 2010) and not to describe the hydrology and its short term influence on juvenile flatfish distribution, low at the end of the summer after a low river flow period in the Bay of Biscay (Le Pape et al., 2003a).

A 3D hydrodynamic model (ECOMARS 3D; Lazure, 2009) was set up over the Bay of Biscay, providing standardized surface salinity from 1972 to 2011 every 6 hours (Huret et al., 2013). Salinity data were extracted from the surface layer and averaged over the first four months of each year (January to April) on each cell of the spatial grid. Surface salinity from January to April is used as an inverse spatialized proxy of estuarine influence which depends on the river flows (the less the surface salinity, the more the river flows). This period has been chosen from previous analysis on $S$. solea, as it is most likely the time at which river discharge reaches its maximum (Le Pape et al., 2003d) and determines trophic chain enrichment (Kostecki et al., 2010), thus nursery habitat and flatfish juveniles spatial distribution during the following critical spring-summer growth period (Le Pape et al., 2003a). In the model, salinity is split into three classes: < 30, ] $30 ; 32$ ] and > 32, which correspond to estuarine waters, mixing zone and marine waters respectively. One annual raster map of average January -April surface salinity was finally available for each year of survey. 


\section{Coastal exposure}

Data from the pre-operational system PREVIMER (http://www.previmer.org/en/produits) provided wave height (in m) every 3 hours, from 2002 to 2011 on a $2 \mathrm{~km}$ horizontal regular grid covering the whole study area. The period selected for averaging wave height (May to August) was chosen for its overlap with the spring-summer growth period of juvenile flatfish on their nursery grounds (Dorel et al., 1991) before the surveys. This average wave height represents the level of wave exposure of coastal and estuarine habitats during the period when 0-group flatfish are the more sensitive to nursery suitability. As the duration of the wave dataset does not cover the trawl survey period (starting in 1980, Table 1), preliminary studies analyzed interannual variability of wave exposure. They showed that, at two different spatial scales (geographic sector and grid cell), this interannual variability of mean wave height from May to August was largely exceeded by spatial variability. Thus mean annual wave heights from May to August were averaged over the available 10y period and used as a proxy for coastal exposure. Averaged wave height was split into three classes: < 0.3] 0.3 ; 0.5$,$] and >0.5$ which correspond to a gradient between sheltered and exposed habitats.

\section{Non retained habitat descriptors}

Though water temperature is available from the 3D hydrodynamic model used to describe estuarine plume, the effect of temperature is not considered in the present study. Indeed, the focus is here on local habitat suitability for juveniles while temperature is known to drive species distribution at much broader scales (Engelhard et al., 2011). For instance, a visible effect of temperature on observed juvenile densities is more likely to reflect the spatial distribution of spawning adult than local juvenile preferences, especially for flatfish (Hermant et al., 2010). In any case, the inability to distinguish the causality link may lead to spurious conclusion about temperature role on juvenile habitat suitability.

Food availability is a driving factor of habitat choice (Kopp et al., 2013) and descriptors of food repartition could improve the description of habitat suitability (Stoner et al., 2001; Le Pape et al., 2007; Nicolas et al., 2007; Kopp et al., 2013). Nevertheless, exhaustive spatial knowledge (needed for mapping) on these biotic factors is not available and prevents their use for habitat mapping. 


\subsection{Coupling trawl survey data and habitat descriptors}

Shapes of bathymetry, sediment structure, salinity and wave height were included into a PostgreSQL (Copyright @ ( 1996-2012 The PostgreSQL Global Development Group) database. Physical descriptors were temporally constant except for salinity (i.e. one annual map of mean salinity from January to April for each year of the study period 1980-2011). Sector limits (Fig. 1) were also inserted into the PostgreSQL database.

Survey data, identified from the mean position of the trawl haul and the year of survey were included in the database. Under PostgreSQL, the location of each trawl haul was intersected with each physical descriptor and sector information. The final dataset consisted in the 1643 selected trawl hauls, associated with the year of survey, 0-group densities for the three species, the geographical sector and the four physical descriptors.

\subsection{Modeling habitat suitability}

Model fit: the delta approach

Three separate species specific EFHS models were built on the 0-group densities. EFHS models were developed using "Salinity", "Sediment structure", "Bathymetry", "Wave height" "Geographical sector" and "Year" as potential descriptive factors of suitability. Abundance indices data are typical zero-inflated data, characterized by an important proportion of zero values. Indeed the presence rates of 0 -group S. solea, P. platessa and D. cuneata were $58.1 \%, 19.5 \%$ and $12.1 \%$ respectively. This non-Gaussian data distribution prohibited the use of a classical statistical approach and Delta-models were used (Stefanson 1996; Martin et al., 2005; Rochette et al., 2010). The Deltamodel is a conditional approach coupling two sub-models: 1) a first testing for the presence; 2) a second explaining the variation of the densities in data where presence was recorded. Three steps are needed to build these models:

For each species separately, the first sub-model describes the binary presence/absence information, $\mathrm{Y}_{0 / 1}$ the Boolean value of juvenile presence (1 when at least one individual from the 0- 
group of the species was caught in the trawl haul, 0 otherwise) being used as the response variable.

The model is a GLM based on a binomial distribution where $Y_{0 / 1}$ depends upon factors through a logit link function (Eq. (4)).

$$
\operatorname{Logit}\left(Y_{0 / 1}\right) \approx \mu_{0 / 1}+F_{\text {Salinity }}+F_{\text {Sediment }}+F_{\text {Bathymetry }}+F_{\text {Wave }}+F_{\text {Sector }}+F_{\text {Year }}+\varepsilon_{0 / 1}
$$

The second sub-model (Eq. (5)) uses a Gaussian linear model on log-transformed positive densities $Y_{+}$to normalize the skewed distribution of the data.

$$
\ln \left(Y_{+}\right) \approx \mu_{+}+F_{\text {Salinity }}+F_{\text {Sediment }}+F_{\text {Bathymetry }}+F_{\text {Wave }}+F_{\text {Sector }}+F_{\text {Year }}+\varepsilon_{+}
$$

Preliminary analyses showed that this option was the best to describe the distribution of positive values (Le Pape et al., 2003b; Rochette et al., 2010).

Habitat suitability for each species can be estimated from the 0 -group density $\hat{Y}$ by combining the two sub-models, accounting for a correction (Laurent, 1963) to obtain an unbiased estimate of the positive densities from a linear model based on log-transformation ( Eq. (6)).

$$
\widehat{Y}=\widehat{Y}_{0 / 1} \times e^{\ln \left(\widehat{Y_{+}}\right)} \times e^{\frac{\widehat{\sigma}^{2}\left(\varepsilon_{+}\right)}{2}}
$$

Simple and cross-over effects were tested to choose the best model for each species. Goodness of fit (GOF) of models was evaluated based on both Chi-square tests for significance (a 5\% threshold for type 1 error has been chosen for an effect to be retained) and Akaike information criterion (AIC), considered to analyze models parsimony.

The delta method is not adapted for the assessment of mean effects from fitted parameters in GLMs. Indeed the combined effects on a binomial distribution and on positive log-transformed data cannot be interpreted together (Ye et al., 2001). Combined (i.e. presence $\times$ positive densities) mean effects have been computed to obtain relative effects of each modality of factor (Rochette et al., 2010) from the following method. Predicts were generated from Eq. (6) on the modeling datasets to obtain models estimates of density for each trawl haul. For one factor, the mean effect of class $c$ of factor $f$ for species $s$ is (Eq. (7)) the mean of all estimated densities on the $\mathrm{n}$ trawl hauls belonging to the class $c$ divided by the overall mean estimated density on the whole dataset (1643 samples).

$$
\text { Mean effect }{ }_{s, f, c}=\frac{\sum_{i}^{n} \hat{Y}_{s, f, c, i} / n}{\sum_{i}^{1643} \hat{Y}_{s, f, c, i} / 1643}
$$




\section{Model validation}

As models with poor and/or biased prediction power could lead to spurious conclusions on EFHS (Planque et al., 2011), their validation requires attention. In order to validate EFHS models, their GOF was evaluated comparing observed versus predicted values (Piñeiro, 2008) with a calibration/validation procedure (Vasconcelos et al., 2013). Datasets of each species have been split in two parts: calibration dataset $-75 \%$ of the data - and validation dataset - the $25 \%$ remaining data. Selection was done with respect to the relative amount of data within the different classes of factors to avoid random selection bias. For each species, binomial and positive models were fitted using the calibration data set and models GOF was tested both on the calibration and the validation data sets by comparing the models predictions with data (juvenile flatfish densities). Predictions are the models fitted values for the calibration dataset and the models estimates for the validation dataset. This methodology allowed evaluating models performance. As the amount of data is lower in the validation dataset, coefficients of determination were expected to be lower for validation data. A moderate decrease in GOF from the calibration dataset to the validation dataset supports accuracy and robustness (Power, 1993; Olden et al., 2002).

Area Under Curve (AUC) of the Receiver Operating Characteristic (Elith et al., 2006; Townsend Peterson et al., 2008) was used to measure accuracy of the binomial models in predicting presence/absence. This analysis considers Boolean values correctly or incorrectly assigned (AUC of 0.5 represents a useless model and AUC of 1 a perfectly fitted model).

The Pearson coefficient of determination between density observed (y-axis) and predicted (x-axis) (Piñeiro et al., 2008) was used to estimate the proportion of the total variance explained by the positive models.

\subsection{Quantitative habitat mapping}

Mapping density with models predicts

To sum up information on flatfish nursery habitat at the Bay of Biscay population scale, the mean distributions of the three species were mapped. For this purpose, three species specific EFHS models were fitted with the same procedure as in 2.4., without including the year effect. The effect of 
interannual variability was removed to build a mean habitat suitability map on which all variations in

0-group relative densities are solely linked to habitat features. Results of these habitat suitability models were included in a GIS to map mean juvenile flatfish distribution. To do so, the mean estuarine plume conditions were calculated (i.e. surface salinity from January to April were averaged over the whole period, from 1980 to 2011) and habitat mapping was based on these average hydrologic conditions. Combining the five levels of spatial information (four physical factors and one geographical sector) under PostgreSQL allowed for habitat strata to be identified. A habitat stratum is defined by one of the six geographic sectors, one of the four classes of bathymetry, one of the four classes of sediment, one of the three classes of wave height and one of the three classes of mean salinity. Thus, using PostgreSQL, a new layer was created as the result of the intersections of the five shapes. This method based on vector maps respects the original resolution of each source of information, to obtain a combined stratification all over the study area.

Model predictions were calculated for each species, providing an estimation of the 0-group density with Eq. (6) for each stratum (i.e each polygon). These predictions were displayed with QGIS software (Quantum GIS Development Team, 2012. Quantum GIS Geographic Information System 1.8. Open Source Geospatial Foundation Project. http://qgis.osgeo.org) to produce maps.

\section{Calculating the contributions of the different habitats}

Predicted values of EFHS models and the GIS were combined to calculate, for each species, the respective contributions of the different habitats at the scale of the Bay of Biscay management unit:

- The surface area of each stratum (Bathymetric class $\times$ Sediment structure $\times$ Salinity class $\times$ Wave height class $\times$ Coastal Sector) was calculated using PostgreSQL

- For each stratum and for each species, a relative number of 0-group juvenile was calculated as the product of this surface area multiplied by the corresponding density value, as predicted by the delta models.

This relative number of fish was used to determine the contribution of the different habitats to the whole stock, at the scale of the Bay of Biscay stock management unit, as a percentage of the total number of fish in the overall area (Le Pape et al., 2003b). 


\section{Results}

\subsection{Selection of descriptors, EFHS models fit and validation}

The four descriptors of nursery habitat, the geographical sector and the interannual variability were retained as explanatory factors in EFHS models for the three species. They contribute to explain both presence and positive densities quite systematically and if not are significant in at least one of the two sub-models, except wave height in the case of D. cuneata (Table 2). No cross-over effect between factors was retained in EFHS models for three reasons: cross-over effects were not significant, were not retained from AIC criterion or presented singularities in some combinations that cannot be estimated because of a lack of degrees of freedom, leading to numerical bias in the estimation.

Binomial sub-models explained from $21 \%$ to $45 \%$ of the deviance in presence data, with better performance for $P$. platessa than for the two other species (Table 2). AUC indices showed great prediction accuracy of Binomial models for all species (Fig. 2 for S. solea and Table 3 for the three species), with moderate loss of the predictive capacity of the models between calibration and validation data.

Positive sub-models explained from 30 to $60 \%$ of the total deviance in positive densities with also better performance for $P$. platessa than for the two other species (Table 2). There were no trends in the residuals of the positive models, which confirmed that Gaussian models on log-transformed densities were appropriate to the distribution of positive densities for juvenile flatfish (Fig. 2). Similar level of performance was reached for positive models from correlations between prediction and data (Fig. 2, Table 3). The loss of predictive capacity of the EFHS models between calibration and validation was $10 \%$ for S. solea and P. platessa and lower (8\%) for D. cuneata.

Thus, even if their power to explain variability in the data appeared limited, the delta models with six descriptive factors were adapted to the 0-inflated lognormal distribution of 0-group flatfish densities and the calibration-validation procedure demonstrated their robustness.

\subsection{Effects of the descriptors on 0-group flatfish densities}


Bathymetry was significant for presence and positive density models for the three flatfish species. This factor is of major influence for $S$. solea and $P$. platess $a$ for which it explains respectively roughly $8 \%$ and $14 \%$ of deviance in both presence and positive density models (Table 2). Bathymetry mean effects confirm the high influence of this factor on S. solea and P. platessa (Fig. 3), with a strong predilection for shallow waters. A drop in estimated density can be observed as bathymetry increases, 0-group densities in the shallower class of bathymetry being about four times higher than the one of the following class $(5-10 \mathrm{~m})$ for both species, with a continuous decrease along the two following classes of bathymetry. D. cuneata seems less influenced by bathymetry.

Sediment type was significant in both presence and positive density models for the three flatfish species. Although sediment structure is of lesser influence than bathymetry, except for $D$. cuneata, some significant patterns are visible on Fig. 3 , S. solea and P. platessa both presenting a strong correlation with mud and D. cuneata with fine sand.

The effect of salinity was also significant in the two sub-models for the three species; however it appears limited as an explaining factor (Table 2). P. platessa shows a high affinity to estuarine waters (Fig. 3), whereas it is less obvious for the two other flatfish species.

Wave height was significant on both presence and positive density of 0-group for S. solea and on the positive density for P. platessa, on which it is particularly influent (Table 2). Mean effects reveal a predilection of $S$. solea and $P$. platessa for sheltered areas, i.e. areas belonging to the lowest wave height class (Fig. 3). Mean effect decreases rapidly as wave height increases for both species. There is no influence of this factor on D. cuneata distribution.

Geographic sector was significant on both presence and density of 0-group for $S$. solea and $P$. platessa while being significant only on presence for D. cuneata (Table 2). Geographic sector is particularly effective to discriminate presence of $P$. platessa and D. cuneata rather than S. solea. These two flatfishes have marked latitudinal trends (Fig. 3): from no occurrence in the Gironde to a northward increase for $P$. platessa, versus a northward decrease for D. cuneata.

Year factor significantly influences presence and positive density of 0-group for all flatfish species with a larger influence on positive density than on presence. Interannual variability is lower than spatial variability (spatial factors) for $S$. solea and $P$. platessa, whereas it is the opposite for $D$. 
cuneata (Table 2). Mean effects provide insights on the interannual variability and temporal trends of density for 0-group (Fig. 4). They reveal opposite trends on two studied species, P. platessa and D. cuneata. The first decreased from the late 1980s to the early 2000s whereas the latter increased over the same period.

\subsection{Mapping: identification of nursery areas and relative habitat contributions}

High densities of 0-group S. solea can be found on restricted coastal areas, near river mouths or in sheltered bays (Fig. 5). The same coastal preference can be observed for P. platessa and D. cuneata although distribution of $D$. cuneata extends a little farther off the coast. For these two species, densities are lower than for S. solea. Opposite latitudinal trends (Fig. 3) induce opposite spatial gradients (Fig. 5), with a southern area of distribution for D. cuneata and a northern one for $P$. platessa.

Across the entire Bay of Biscay (i.e. at the scale of stocks management unit) the respective contributions of different habitats to the total amount of juvenile flatfish were calculated (Table 4). Shallow waters appeared essential for S. solea and P. platess $a$ with more than $75 \%$ of the total amount of 0-group located in the shallowest class $(<5 \mathrm{~m})$ of bathymetry, this concentration being lower for $D$. cuneata. Muddy areas mainly contribute to the total population of 0 -group fish for $S$. solea and $P$. platessa, with contributions higher than $75 \%$. On the contrary, fine sand appeared essential for $D$. cuneata. Shallow $(<5 \mathrm{~m})$ areas covered by mud and fine sand appeared essential for the total amount of 0-group flatfish. When the three species are summed, these habitats contribute for $70 \%$ of the flatfish juvenile in the Bay of Biscay, while accounting for only $20 \%$ of the surface of coastal areas $(\leq 35 \mathrm{~m})$ off the Bay of Biscay. Sheltered areas (Wave height $<0.3 \mathrm{~m}$ ) appear especially suitable, hosting two thirds (68\%) of juvenile $S$. solea. Shallow sheltered areas covered by mud and fine sand represent $8 \%$ only of the coastal zone but host almost half (48\%) of the total amount of juvenile flatfish, when the three species are accounted for.

\section{Discussion}




\subsection{Relevance of the method}

Marine fish abundance survey data are often zero-inflated, with associated high variability in the remaining positive data (Stefansson, 1996). The beam trawl survey data used in the present study display an important proportion of zeros accentuated by the selection of a particular life stage (0group). The delta method implemented in this study enables to process such zero-inflated data. Delta models are commonly used for 0-inflated data (Stefánsson, 1996; Welsh et al., 1996; Brynjarsdóttir and Stefánsson, 2004). However, the delta model presents some limits related to the correlation between the two datasets (presence-absence and positive density). Indeed, the construction of the two sub-models relies on the hypothesis that the probability of presence and the distribution of the positive catch are independent (Fletcher 2008; Calama et al., 2011). However, data reveal that sites with a high probability of presence are also harboring high densities. Presence and density can therefore not be considered as independent and the bias introduced by the calculation of the estimated density as the product of the two probabilities is unknown. Alternative methods, e.g. compound Poisson process (Ancelet et al., 2010) or Tweedie distribution (Shono, 2008), have been implemented to analyze and solve this bias. They provided results similar to those produced by the delta method but were more complicated to implement and less parsimonious. The delta method was therefore retained as it was the most straightforward to fulfill the objectives of the study. Moreover, a main interest of the delta method is the separate analysis of the probability of presence on the one hand and the level of positive catch on the other hand. Such segregation enables a more refined analysis with different variables accounting for the two sub-models and ecological interpretations can emerge (Ye et al., 2001; Le Pape et al., 2004). Indeed, the present study revealed a higher influence of wave height and interannual variability on positive densities than on probability of presence. These two factors appeared more influent in modulating density than spatial extent of juvenile flatfish.

A validation process separating a calibration and a validation dataset was used to evaluate the robustness of EFHS models. The prediction of responses based on new data sets provided a mean to estimate how accurate were the models predictions when using external data (Planque et al., 2011; Vasconcelos et al., 2013). With reasonably lower GOF on calibration data than on validation data, this procedure validated the two sub-parts of the EFHS models for the three studied flatfish species. The 
similarities between the model developed for S. solea only and a previous approach (Le Pape et al., 2003b) also contributed to this validation. The previous dataset was upgraded with ten years of data (44\% of additional data) furthermore including data from the inner part of rivers, which were totally new locations. Despite this tremendous change, results on $S$. solea highlighted the same general patterns. This consistency can therefore be considered as another confirmation of the robustness of the method and its appropriateness to study juvenile flatfish habitat suitability.

\subsection{Nursery habitat suitability for S. solea: confirmed knowledge, new insights and remaining gaps}

The preference of juvenile S. solea for shallow areas (Gibson, 1997) covered with fine sediment was previously established (Le Pape et al., 2003b). The present EFHS models-GIS coupled approach confirmed that shallow $(<5 \mathrm{~m})$ and muddy grounds contribute greatly to the total population of 0-group from S. solea and can be considered as essential nursery habitats for this species. They harbor nearly two thirds of the total amount of juvenile $S$. solea, while representing only $16 \%$ of the overall coastal study area. Besides, locations deeper than $20 \mathrm{~m}$ and grounds not covered with fine sediment are unsuitable as nursery grounds for S. solea.

Coastal exposure affects habitat structure, which might influence settling behavior and survival of juvenile fish. Juvenile flatfish prefer sheltered parts of the coast and embayments (Pihl and Van der Veer, 1992; Howell et al., 1999) and this preference was suggested for S. solea (Le Pape et al., 2003b). However, no parameter had previously been included in EFHS models to quantify the link between sheltered places and high densities of 0-group S. solea. The addition of wave height as a proxy of coastal exposure to explain spatial distribution in EFHS models for juvenile $S$. solea quantified the significant negative influence of wave exposure on habitat suitability. Wave exposure affects sediment structure, an important factor of suitability for juvenile flatfish (Gibson and Robb, 2000) and this could explain its influence on flatfish nursery suitability (Pihl and Van der Veer, 1992; Howell et al., 1999). Nevertheless, this influence was taken into account in the developed EFHS models by a specific descriptor based on granulometry. By adding information to EFHS models 
including sediment description, the present models demonstrate that wave exposure can be considered

as a cause of physical perturbation on the bottom sediment for young flatfish, affecting habitat suitability in addition to its effect on sediment granulometry. Indeed, wave induces currents and bed stress, which can alter survival during larval settlement and metamorphosis and also nursery habitat structure and complexity (Polte et al., 2005), with consequences on suitability for juvenile flatfish. In EFHS models for juvenile S. solea, this influence explains half as much deviance as the remaining spatial variability (itself explained by differences between geographical sectors). Indeed, compared to the results of Le Pape et al. (2003b) the mesoscale variability (i.e. Sector effect) has dramatically decreased, from $11.8 \%$ (presence) and $20.9 \%$ (positive) in the previous sub-models for S. solea to $3.1 \%$ and $4.7 \%$ now, respectively. The effect of wave exposure should have been even more important if the central part of the bay, between Bays of Bourgneuf and Pertuis Breton (Fig. 1), previously shown as not suitable as nursery ground (Le Pape et al., 2003b) and largely exposed to wave, had been included in the study. Wave exposure has therefore to be considered as an unavoidable explanatory variable of EFHS for 0-group S. solea. Shallow protected habitats are highly utilized as nurseries for 0-group flatfish and deserve special attention in management or conservation efforts (Fodrie and Mendoza, 2006).

However, in the present study the percentage of deviance unexplained by the EFHS model for juvenile S. solea reaches $79 \%$ and $68 \%$ for the presence and positive densities sub-models respectively. Four sources of remaining variability could explain this result:

- Restricted study area. In spite of the use of additional explaining factors, the proportion of variance explained by the present models was not improved with regards to the previous (Le Pape et al., 2003b) approach (21\% here vs $23 \%$ previously and $32 \%$ vs $29 \%$ for the presence and the positive sub-models respectively). One could consider the new EFHS model for S. solea as less performing with regards to its similar explained variability but lower parsimony. Nevertheless, it is important to note that the present dataset focused on nursery areas, restricted to bathymetry $\leq 35 \mathrm{~m}$ (50m before) and to favorable sectors (i.e. excluding the unsuitable areas in central part of the Bay of Biscay). This focus on nursery sectors with lessened contrasts (between areas where 0-group catches were scarce, excluded here, to the suitable habitats included in the present study) limits the apparent explanatory 
power of models. Due to these differences in the constitution of the dataset, the present models with additional descriptors improve previous description of EFHS in spite of a similar explained variance.

- A raw description of habitat drivers. The arbitrary choice of mean surface salinity from January to April to describe the estuarine plume does not reflect the local continuous ecological processes (Greenwood, 2007) involved in S. solea estuarine dependence at juvenile stages (Courrat et al., 2009; Le Pape et al., 2013). Accordingly, a better explanatory variable than sediment type in three different classes could improve EFHS models (Stoner et al., 2001).

- Additional drivers of habitat suitability. Biotic conditions (e.g. food availability and predation) are essential driving factors of habitat choice and could be selected considering their widely acknowledged influence on the distribution of juveniles (Diaz et al., 2003; Adams et al., 2004). Especially, descriptors of the benthic food source could contribute to significantly improve the description (Stoner et al., 2001; Le Pape et al., 2007; Nicolas et al., 2007). Habitat changes related to invasive species, such as presence of Crepidula fornicata (Le Pape et al., 2004; Kostecki et al., 2011) or proliferation of green algae (Pihl et al., 2006; Wennhage et al., 2007) could also be considered for their strong negative effects. Nevertheless, exhaustive spatial knowledge (needed for mapping) on biotic factors is seldom available and habitat mapping is here, and in general predominantly, based on abiotic factors only.

- Estimation error. Small-scale variability occurs in patchy juvenile flatfish distribution (Allen and Baltz, 1997; Rogers, 1992) and could not be reflected by sampling units covering several thousands of square meters. Moreover, uncertainty in estimates related to survey conditions (Poulard and Trenkel, 2007) prevent EFHS models from achieving a complete description of 0 group S. solea densities.

\subsection{Generalization to coastal and estuarine dependent flatfish species}

With regards to EFHS models for S. solea, the present study reveals levels of models performance similar for D. Cuneata and higher for P. Platessa, and comparable patterns. Dependence to shallow muddy areas appears stronger for P. platessa than for S. solea in the Bay of Biscay. The relationship between nursery grounds and estuarine productive areas is also supported for this species. 
This preference of $P$. platessa for shallow productive muddy areas at juvenile stages confirmed previous observations in the Eastern Channel (Riou et al., 2001), the Irish Sea (Nash et al., 2007), the North Sea (Bolle et al., 2009) and the Baltic Sea (Wennhage and Pihl, 2001). Wave height is also highly significant for P. platessa on positive density of 0-group and explains twice as much deviance as the remaining mesoscale variability. This preference of $P$. platessa for sheltered coastal areas was also previously evidenced (Pihl and Van der Veer, 1992). On the contrary, D. cuneata presented differences in spatial distribution compared to S. solea and P. platessa. Juvenile of D. cuneata were distributed towards deeper water and depended on sea floor covered with fine sand for nursery. Nor has waves height showed significant influence on D. cuneata and dependence to sheltered areas cannot be generalized. Distribution and habitat of juvenile D. cuneata are closer to these of Buglossidium luteum, a smaller and non-commercial flatfish species living in less shallow soft bottoms (Amara et al., 2007). Nevertheless, locations deeper than $20 \mathrm{~m}$ are also unsuitable as nursery grounds for $D$. cuneata, as were grounds covered by coarse sand, gravel and rock. Thus, shallow coastal areas can be considered as EFH for flatfish, with niche contrast among species. In addition, coastal areas are capable of functioning interchangeably with polyhaline estuarine regions as nursery habitat (Able et al.,2005; Kostecki et al., 2012; Woodland et al., 2012; Le Pape et al., 2013), with interannual variations related to river flow conditions (Le Pape et al., 2003a; Darnaude, 2005).

P. platessa and D. cuneata showed mesoscale gradients linked to latitudinal trends. Their abundances respectively increased and decreased as latitude increased, in response to their biogeographical distribution. The Bay of Biscay is respectively the southern and northern limit of distribution for these two species (Désaunay et al., 2006; Hermant et al., 2010). Accordingly, strong temporal trends were revealed for these two species: dramatic reduction, close to disappearance, of $P$. platessa from the early 1990s to the mid-2000s and progressive increase of D. cuneata from the late 1990s. These trends were confirmed to come from a warming of the waters in the Bay of Biscay, impacting both northern (e.g. P. platessa; Engelhard et al., 2011) and southern (e.g. D. cuneata) flatfish oppositely (Hermant et al., 2010). Both these mesoscale and temporal patterns contributed to lessen the relative influence of local habitat in EFHS models for these two species, by increasing contrasts between geographical sectors and along the three decades of surveys. 


\subsection{From habitat suitability to coastal habitat function and management}

The functionality of key fish habitats, such as nursery grounds (van der Wolfshaar et al., 2011) is essential to sustain marine fish population's renewal (Iles and Beverton, 2000). More consideration should be given to the conservation of nursery habitats and their ability to sustain commercial stocks (Nagelkerten et al., 2012).

The present approach highlighted the usefulness of quantitative maps for management purposes. It is possible to predict geographic distributions of species by life stages from habitat mapping approaches (Rubec et al., 1999; Martin et al., 2009; Lauria et al., 2011). EFHS maps allow for the quantitative identification of the different habitats required for marine resources to complete their life cycle and enable to measure their respective importance for population renewal. They may serve as input in conservation-planning approach which aims to select relevant protected areas. Habitat suitability maps constitute essential elements for prioritizing areas for conducting spatial ecosystem assessments and conservation actions (Brown et al., 2000; Cogan et al., 2009; Le Pape et al., in press). By providing information needed to preserve essential fish habitats (Stoner, 2003), they may solve questions about what exactly constitutes high-value or even critical fish habitat for exploited species (Fodrie and Mendoza, 2006).

The protection of restricted shallow soft bottom sheltered areas, which harbor high proportion of 0-group for estuarine and coastal nursery dependent flatfish species, appear to be a priority for the conservation of these species. They gather a large amount of the total 0-group population in a small area and are therefore essential and effective to insure fish stock renewal (Beck et al., 2001).

\section{Acknowledgements}

This research was partly founded by the European Community's Seventh Framework Programme project "Vectors of Change in Oceans and Seas Marine Life, Impact on Economic Sectors" (VECTORS). We thank many colleagues for providing us with their data and especially Anne Laure Barillé (Bio-littoral) for beam trawl survey data in the Loire estuary, Sébastien Rochette (Ifremer) for the bathymetry map but also for many other supports, Sylvain Cerisier (GIP Loire estuaire) for the map of sediment structure in the Loire estuary, Martin Huret (Ifremer) and Loïc Baulier (Agrocampus 
Ouest) for hydrodynamics model outputs and Franck Dumas (Ifremer) for maps of wave height. We are grateful to Rita Vasconcelos (University of Lisbon), Etienne Rivot (Agrocampus Ouest) and Stéphanie Mahévas (Ifremer) for statistical advice and to Sophie Pasquier (Agrocampus Ouest) for compiling references. We also would like to thank Mike Elliott, the editor, Joel Fodrie (University of North Carolina) and the two other anonymous reviewers for their helpful advice and significant improvements of the manuscript.

\section{References}

Able, K.W., 2005. A re-examination of fish estuarine dependence: Evidence for connectivity between estuarine and ocean habitats. Estuarine, Coastal and Shelf Science 64 (1), 5-18.

Adams, A.J., Locascio, J.V., Robbins, B.D., 2004. Microhabitat use by a post-settlement stage estuarine fish: evidence from relative abundance and predation among habitats. Journal of Experimental Marine Biology and Ecology 299, 17-33.

Allen, R.L., Baltz, D.M., 1997. Distribution and microhabitat use by flatfishes in a Louisiana estuary. Environmental Biology of Fishes 50, 85-103.

Amara, R., Meziane, T., Gilliers, C., Hermel, G., Laffargue, P., 2007. Growth and condition indices in juvenile sole Solea solea measured to assess the quality of essential fish habitat. Marine Ecology Progress Series 351, 201-208.

Ancelet, S., Etienne, M.P., Benoît, H., Parent, E., 2010. Modelling spatial zero-inflated continuous data with an exponentially compound Poisson process. Environmental and Ecological Statistics $17,347-376$.

Anonymous, 1998. Report of the Working Group on Crangon fisheries and life history. ICES CM/G: 8.

Anonymous, 2011. Report of the ICES advisory committee. ICES Advice, 2011. Book 7: Bay of Biscay and Atlantic Iberian Waters. 118 pp. 
Beck, M.W., Heck, K.L., Able, K.W., Childers, D.L., Eggleston, D.B., Gillanders, B.M., Halpern, B., Hays, C.G., Hostino, K., Minello, T.J., Orth, R.J., Sheridan, P., Weinstein, M.P., 2001. The role of nearshore ecosystems as fish and shellfish nurseries. Bioscience 51 (8), 633-641.

Bolle L.J., Dickey-Collas M., Van Beek J.K.L., Erftemeijer P.L.A., Witte J.I.J., Van der Veer H.W., Rijnsdorp A.D., 2009. Variability in transport of fish eggs and larvae. III. Effects of hydrodynamics and larval behaviour on recruitment in plaice. Marine Ecology Progress Series 390, 195-211.

Brind'Amour, A., Lobry J. 2009. Assessment of the ecological status of coastal areas and estuaries in France, using multiple fish-based indicators: a comparative analysis on the Vilaine estuary. Aquatic Living Resources, 22(4), 559-572.

Brown, K.W., Buja, K.R., Jury, S.H., Monaco, M.E., Banner, A., 2000. Habitat suitability index models for eight fish and invertebrate species in Casco and sheepscot bays, Maine. North American Journal of Fisheries Management 20, 408-435.

Brynjarsdóttir, J., Stefánsson, G., 2004. Analysis of cod catch data from Icelandic groundfish surveys using generalized linear models. Fisheries Research 70, 195-208.

Calama, R., Mutke, S., Tomé, J., Gordo, J., Montero, G., Tomé, M., 2011. Modelling spatial and temporal variability in a zero-inflated variable: The case of stone pine (Pinus pinea L.) cone production. Ecolical Modelling 222, 606-618.

Cogan, C.B., Todd, B.J., Lawton, P., Noji, T.T., 2009. The role of marine habitat mapping in ecosystem based management. ICES Journal of Marine Science 66, 2033-2042.

Courrat, A., Lobry, J., Nicolas, D., Laffargue, P., Amara, R., Lepage, M., Girardin, M., Le Pape, O., 2009. Anthropogenic disturbance on nursery function of estuarine areas for marine species. Estuarine, Coastal and Shelf Science 81, 179-190.

Darnaude, A.M., 2005. Fish ecology and terrestrial carbon use in coastal areas: implications for marine fish production. Journal of Animal Ecology 74, 864-876. 
Delpech, C., Courrat, A., Pasquaud, S., Lobry, J., Le Pape, O., Nicolas, D., Boët, P., Girardin, M., Lepage, M., 2010. Development of a fish-based index to assess the ecological quality of transitional waters: the case of French estuaries. Marine Pollution Bulletin. 60, 908-918.

Desaunay, Y., Guerault, D., Le Pape, O., Poulard, J.C., 2006. Changes in occurrence and abundance of northern/southern flatfishes over a 20-year period in a coastal nursery area (Bay of Vilaine) and on the eastern continental shelf of the Bay of Biscay. Scientia Marina 70, 193-200.

Diaz, R.J., Cutter, G.R., Able, K.W., 2003. The importance of physical and biogenic structure to juvenile fishes on the shallow inner continental shelf. Estuaries 26, 12-20.

Dorel, D., Koutsikopoulos, C., Desaunay, Y., Marchand, J., 1991. Seasonal distribution of young sole (Solea solea (L.)) in the nursery ground of the Bay of Vilaine (Northern Bay of Biscay). Netherlands Journal of Sea Research 27, 297-306.

Eastwood, P.D., Meaden, G.J., Carpentier, A., Rogers, S.I., 2003. Estimating limits to the spatial extent and suitability of sole (Solea solea) nursery grounds in the Dover Strait. Journal of Sea Research 50, 151-165.

Elith, J., Graham, C., Anderson, R., Dudik, M., Ferrier, S., Guisan, A., Hijmans, R., Huettmann, F., Leathwick, J., Lehmann, A., Li, J., Lohmann, L., Loiselle, B.A., Manion, G., Moritz, C., Nakamura, M., Nakazawa, Y., Overton, J.M.C.M., Peterson, A.T., Phillips, S., Richardson, K., Scachetti-Pereira, R., Schapire, R., Soberón, J., Williams, S., Wisz, M., Zimmermann., N., 2006. Novel methods improve prediction of species' distributions from occurrence data. Ecography 29, 129-151.

Engelhard, G., Pinnegar, J., Kell, L.T., Rijnsdorp, A.D., 2011. Nine decades of North Sea sole and plaice distribution. ICES Journal of Marine Science 68, 1090-1104.

Fletcher, D., 2008. Confidence intervals for the mean of the delta-lognormal distribution. Environmental and Ecological Statistics 15, 175-189.

Fodrie, F.J., Levin, L.A., Lucas, A.J., 2009. Use of population fitness to evaluate the nursery function of juvenile habitats. Marine Ecology-Progress Series 385, 39-49. 
Fodrie, F.J., Mendoza, G., 2006. Availability, usage and expected contribution of potential nursery habitats for the California halibut. Estuarine Coastal and Shelf Science 68, 149-164.

França, S., Vasconcelos, R., Fonseca, V., Tanner, S., Reis-Santos, P., Costa, M., Cabral, H., 2012. Predicting fish community properties within estuaries: Influence of habitat type and other environmental features. Estuarine, Coastal and Shelf Science 107, 22-31.

Fulford, R.S., Peterson, M.S., Grammer, P.O., 2011. An ecological model of the habitat mosaic in estuarine areas: Part I- Interaction of dispersal theory and habitat variability in describing juvenile fish distribution. Ecological Modelling 222, 3203-3215.

Gibson, R.N., 1994. Impact of habitat quality and quantity on the recruitment of juvenile flatfishes. Netherlands Journal of Sea Research 32, 191-206.

Gibson, R.N., 1997. Behaviour and the distribution of flatfishes. Journal of Sea Research 37, 241-256.

Gibson, R.N., Robb, L. 2000. Sediment selection in juvenile plaice and its behavioural basis. Journal of Fish Biology 56, 1258-1275.

Greenwood, M.F.D, 2007. Nekton community change along estuarine salinity gradients: can salinity zones be defined. Estuaries and Coasts 30 537-542.

Halpern, B.S., Selkoe, K.A., Michelli, F., Kappel, C.V., 2007. Evaluating and tanking the vulnerability of global marine ecosystems to anthropogenic threats. Conservation Biology 21, 1301-1315.

Halpern, B.S., Walbridge, S., Selkoe, K.A., Kappel, C.V., Micheli, F., D’Agrosa, C., Bruno, J.F., Casey, K.S., Ebert, C., Fox, H.E., Fujita, R., Heinemann, D., Lenihan, H.S., Madin, E.M.P., Perry, M.T., Selig, E.R., Spalding, M., Steneck, R., Watson, R., 2008. A global map of human impact on marine ecosystems. Science 319, 948-952.

Hermant, M., Lobry, J., Bonhommeau, S., Poulard, J.C., Le Pape, O., 2010. Impact of warming on abundance and occurrence of flatfish populations in the Bay of Biscay (France). Journal of Sea Research 64, 45-53. 
Howell, P.T., Molnar, D.R., Harris, R.B., 1999. Juvenile winter flounder distribution by habitat type. Estuaries 22, 1090-1095.

Huret, M., Sourisseau, M., Petitgas, P., Struski, C., Leger, F., Lazure, P., 2013. A multidecadal hindcast of a physical-biogeochemical model and derived oceanographic indices in the Bay of Biscay. Journal of Marine Systems. 109-110, S77-S94.

Iles, T.C., Beverton, J.H., 2000. The concentration hypothesis: the statistical evidence. ICES Journal of Marine Science 57, 216-227.

Kopp, D., Le Bris, H., Grimaud, L., Nérot, C., Brind'Amour, A., 2013. Spatial analysis of the trophic interactions between two juvenile fish species and their preys along a coastal estuarine gradient. Journal of Sea Research 81, 40-48.

Kostecki, C., Le Loc'h, F., Roussel, J.M., Desroy, N., Huteau, D., Le Bris, H., Le Pape, O., 2010. Dynamics of an estuarine nursery ground: the spatio-temporal relationship between the river flow and the food web of the juvenile common sole (Solea solea, L.) as revealed by stable isotopes analysis. Journal of Sea Research 64, 54-60.

Kostecki, C., Rochette, S., Girardin, R., Blanchard, M., Desroy, N., Le Pape, O., 2011. Reduction of flatfish habitat as a consequence of the proliferation of an invasive mollusk. Estuarine, Coastal and Shelf Science 92, 154-160.

Kostecki, C., Roussel, J.M., Desroy, N., Roussel, G., Lanshere, J., Le Bris, H., Le Pape, O., 2012. Trophic ecology of juvenile flatfish in a coastal nursery ground: contributions of intertidal primary production and freshwater particulate organic matter. Marine Ecology-progress Series $449,221-232$.

Koutsikopoulos, C., Fortier, L., Gagne, J.A., 1991. Cross-well dispersion of dover sole (Solea solea (L.)) eggs and larvae in Biscay Bay and recruitment to inshore nurseries. Journal of Plankton Research 13, 923-945. 
Laurent, A.G., 1963. The log-normal distribution and the translation method: description and estimation problems. Journal of the American Statistical Association 58, 231-235.

Lauria, V., Vaz, S., Martin, C.S., Mackinson, S., Carpentier, A. 2011. What influences European plaice (Pleuronectes platessa) distribution in the Eastern English Channel? Using habitat modelling and GIS to predict habitat utilization. ICES Journal of Marine Science 68, 15001510.

Lazure, P., Garnier, V., Dumas, F., Herry, C., Chifflet, M., 2009. Development of a hydrodynamic model of the Bay of Biscay. Validation of hydrology. Continental Shelf Research 29, 985-997.

Le Pape, O., Baulier, L., Cloarec, A., Martin, J., Le Loc'h, F., Desaunay, Y., 2007. Habitat suitability for juvenile common sole (Solea solea, L.) in the Bay of Biscay (France): A quantitative description using indicators based on epibenthic fauna. Journal of Sea Research 57, 126-136.

Le Pape, O., Chauvet, F., Désaunay, Y., Guérault, D., 2003a. Relationship between interannual variations of the river plume and the extent of nursery grounds for the common sole (Solea solea, L.) in Vilaine Bay. Effects on recruitment variability. Journal of Sea Research 50, 177185.

Le Pape, O., Chauvet, F., Mahevas, S., Lazure, P., Guerault, D., Desaunay, Y., 2003b. Quantitative description of habitat suitability for the juvenile common sole (Solea solea, L.) in the Bay of Biscay (France) and the contribution of different habitats to the adult population. Journal of Sea Research 50, 139-149.

Le Pape, O., Désaunay, Y., Guérault, D., 2003d. Relationship between fluvial discharge and sole (Solea solea, L.) recruitment in the Bay of Biscay (France). Study of an estuarine nursery ground and application on a stock scale. ICES Marine Science Symposia, 219, 241-248.

Le Pape, O., Guerault, D., Desaunay, Y., 2004. Effect of an invasive mollusc, American slipper limpet Crepidula fornicata, on habitat suitability for juvenile common sole Solea solea in the Bay of Biscay Marine. Ecology Progress Series 277, 107-115. 
Le Pape, O., Moderan, J., Beaunée, G., Riera, P., Nicolas, D., Savoye, N., Harmelin-Vivien, M., Darnaude, A., Brind'Amour, A., Le Bris, H., Cabral, H., Vinagre, C., Pasquaud, S., Franca, S., Kostecki, C., 2013. Sources of organic matter for flatfish juveniles in coastal and estuarine nursery grounds; A meta-analysis for the common sole (solea solea) in contrasted systems of Western Europe. Journal of Sea Research 75, 86-95.

Levin, P.S., Stunz, G.W., 2005. Habitat triage for exploited fishes: can we identify essential fish habitat? Estuarine Coastal and Shelf Science 64, 70-78

Martin, C.S., Carpentier, A., Vaz, S., Coppin, F., Curet, L., Dauvin, J.C., Delavenne, J., Dewarumez, J.M., Dupuis, L., Engelhard, G., Foveau, A., Garcia, C., Gardel, L., Harrop, S., Just, R., Koubbi, P., Lauria, V., Meaden, G.J., Morin, J., Ota, Y., Rostiaux, E., Smith, R.J., Spilmont, N., Vérin, Y., Villanueva, C., Warembourg, C., 2009. The Channel habitat atlas for marine resource management (CHARM): an aid for planning and decision-making in an area under strong anthropogenic pressure. Aquatic Living Resources 22, 499-508.

Martin, T.G., Wintle, B.A., Rhodes, J.R., Kuhnert, P.M., Field, S.A., Low-Choy, S.J., Tyre, A.J., Possingham, H.P., 2005. Zero tolerance ecology: improving ecological inference by modelling the source of zero observations. Ecology Letters 8, 1235-1246.

Maxwell, D.L., Stelzenmüller, V., Eastwood, P.D., Rogers, S.I., 2009. Modelling the spatial distribution of plaice (Pleuronectes platessa), sole (Solea solea) and thornback ray (Raja clavata) in UK waters for marine management and planning. Journal of Sea Research, 61, 258-267.

Miller, J.M., Reed, J.P., Pietrafesa, L.J., 1984. Patterns, mechanisms and approaches to the study of migrations of estuarine dependent fish larvae and juveniles. In: J.D., McCleave, J.D., Arnold, G.P., Dodson, J.J., Neill, W.H. (Eds), Mechanisms of migration in fishes Plenum. Press, New York, pp 209-225.

Nagelkerten, I., Grol, M.G.G., Mumby, P.J., 2012. Effects of marine reserves versus nursery habitat availability on structure of reef fish communities. PLOS One 7(6), e36906. 
Nash, R.D.M., Geffen, A.J., Burrows, M.T., Gibson, R.N., 2007. Dynamics of shallow-water juvenile flatfish nursery grounds: application of the shelf-thinning rule. Marine Ecology Progress Series $344,231-244$.

Nicolas, D., Lobry, J., Le Pape, O., Boët, P., 2010. Functional diversity in European estuaries: Relating the composition of fish assemblages to the abiotic environment. Estuarine, Coastal and Shelf Science 88, 329-338.

Nicolas, D., Le Loc'h, F., Désaunay, Y., Hamon, D., Blanchet, A., Le Pape, O., 2007. Relationships between benthic macrofauna and habitat suitability for juvenile common sole (Solea solea, L.) in the Vilaine estuary (Bay of Biscay, France) nursery ground. Estuarine, Coastal and Shelf Science 73, 639-650.

Olden, J.D., Jackson, D.A., Peres-Neto, P.R., 2002. Predictive Models of Fish Species Distributions: A Note on Proper Validation and Chance Predictions. Transactions of the American Fisheries Society $131,329 \square 336$

Peterson, C.H., Summerson, H.C., Thomson, E., Lenihan, H.S., Grabowski, J., Manning, L., Micheli, F., Johnson, G., 2000. Synthesis of linkages between benthic and fish communities as key to protecting essential fish habitat. Bulletin of Marine Science 66, 759-774.

Pihl, L., Modin, J., Wennhage, H., 2000. Spatial distribution patterns of newly settled plaice (Pleuronectes platessa L.) along the Swedish Skagerrak archipelago. Journal of Sea Research $44,65-80$

Pihl, L., Baden, S., Kautsky, N., Ronnback, P., Soderqvist, T., Troell, M., Wennhage, H., 2006. Shift in assemblage structure due to loss of seagrass Zostera marina habitat sin Sweden. Estuarine, Coastal and Shelf Science 67, 123-132.

Pihl, L., Van der Veer, H.W., 1992. Importance of exposure and habitat structure for the population density of 0-group plaice, Pleuronectes platessa L., in coastal nursery areas. Netherlands Journal of Sea Research 29, 145-152. 
Piñeiro, G., Perelman, S., Guerschman, J.P., Paruelo, J.M., 2008. How to evaluate models: Observed vs. predicted or predicted vs. observed? Ecological Modelling 216, 316-322.

Planque, B., Loots, C., Petitgas, P., Lindstrom, U., Vaz, S., 2011. Understanding what controls the spatial distribution of fish populations using a multi-model approach. Fisheries Oceanography $20,1-17$.

Polte, P., Schanz, A., Asmus, H., 2005. Effects of current exposure on habitat preference of mobile 0group epibenthos for intertidal seagrass beds (Zostera noltii) in the northern Wadden Sea. Estuarine, Coastal and Shelf Science 62, 627-635.

Poulard, J.C., Trenkel, V., 2007. Do survey design and wind conditions influence survey indices ? Canadian Journal of Fisheries and Aquatic Sciences, 64(11), 1551-1562.

Power, M., 1993. The predictive validation of ecological and environmental models. Ecological Modelling 68, 33-50.

Rijnsdorp, A.D., Van Beek, F.A., Flatman, S., Millner, R.M., Riley, J.D., Giret, M., De Clerck, R. 1992. Recruitment of sole stocks, Solea solea (L.), in the Northeast Atlantic. Netherlands Journal of Sea Research 29, 173-192.

Riou P., Le Pape, O., Rogers, S.I., 2001. Relative contributions of different sole and plaice nurseries to the adult population in the Eastern Channel: application of a combined method using generalized linear models and a geographic information system. Aquatic Living Resources 14, $125-135$.

Rochette, S., Rivot, E., Morin, J., Mackinson, S., Riou, P., Le Pape, O., 2010. Effect of nursery habitat degradation on flatfish population: Application to Solea solea in the Eastern Channel (Western Europe). Journal of Sea Research 64, 34-44.

Rogers, S.I., 1992. Environmental factors affecting the distribution of sole (Solea solea(L.)) within a nursery area. Netherlands Journal of Sea Research 29, 153-161. 
Rubec, P.J., Bexley, J.C.W., Norris, H., Coyne, M.S., Monaco, M.E., Smith, S.G., Ault, J.S., 1999. Suitability modeling to delineate habitat essential to sustainable fisheries. American Fisheries Society Symposium 22, 108-133.

Shono, H., 2008. Application of the Tweedie distribution to zero-catch data in CPUE analysis. Fisheries Research 93, 154-162.

Stefànsson, G., 1996. Analysis of groundfish survey abundance data: combining the GLM and delta approaches. ICES Journal of Marine science 53, 577-588.

Stoner, A.W., 2003. What constitutes essential nursery habitat for a marine specis ? A case study of habitat form and function for queeen conch. Marine Ecology-Progress Series 257, 275-289.

Stoner, A.W., Manderson, J.P., Pessuti, J.P., 2001. Spatially explicit analysis of estuarine habitat for juvenile winter flounder: combining generalized additive models and geographic information systems. Marine Ecology Progress Series 213, 253-271.

Townsend Peterson, A., Papes, M., Soberón, J., 2008. Rethinking receiver operating characteristic analysis applications in ecological niche modeling. Ecological Modelling 213, 63-72.

Van der Veer, H.W., Koot, J., Aarts, G., Dekker, R., Diderich, W., Freitas, V., Witte, J.I.J., 2011. Long-term trends in juvenile flatfish indicate a dramatic reduction in nursery function of the Balgzand intertidal, Dutch Wadden Sea Marine. Ecology Progress Series 434, 143-154.

Van de Wolfshaar, K.E., HilleRisLambers, R., Gardmark, A., 2011. Effect of habitat productivity and exploitation on populations with complex life cycles. Marine Ecology Progress Series 438, 175184.

Vasconcelos, R., Reis-Santos, P., Maia, A., Fonseca, V., Franca, S., Wouters, N., Costa, M., Cabral, H., 2010. Nursery use patterns of comemrcially important marine fish species in estuarine systems along the portuguese coast. Estuarine, Coastal and Shelf Science 86, 613-624.

Vasconcelos, R.P., Le Pape, O., Costa, M.J., Cabral, H.N. 2013. Predicting estuarine use patterns of juvenile fish with Generalized Linear Models. Estuarine, Coastal and Shelf Science 120, 64-74. 
Welsh, A.A., Cunningham, R.B., Donnelly, C.F., Lindenmayer, D.B., 1996. Modelling the abundance of rare species: statistical models for counts with extra zeros. Ecological Modelling 88, 297308.

Wennhage, H., Pihl, L., 2001. Settlement patterns of newly settled plaice (Pleuronectes platessa) in a non tidal Swedish fjord in relation to larval supply and benthic predators. Marine Biology 139, $877-889$

Wennhage, H., Pihl, L., Stal, J., 2007. Distribution and quality of plaice nursery grounds on the Swedish west coast. Journal of Sea research 57, 218-229.

Woodland, R.J., Secor, D., Fabrizio, M.C., Wilberg, M.J., 2012. Comparing the nursery role of inner continental shelf and estuarine habitats for temperate marine fishes. Estuarine, Coastal and Shelf Science 99, 61-73.

Ye, Y., Al-Husaini, M., Al-Baz, A., 2001. Use of generalized linear models to analyze catch rates having zero values: the Kuwadriftnet fishery. Fisheries Research 53, 151-168. 
Table 1: Synthesis of used data (habitat descriptors and juvenile flatfish surveys)

\begin{tabular}{|c|c|c|c|}
\hline & \multirow[b]{2}{*}{ Spatio-temporal extent } & \multirow[b]{2}{*}{ Features } & \multirow[b]{2}{*}{ Source } \\
\hline & & & \\
\hline \multicolumn{4}{|l|}{ Physical descriptors } \\
\hline Bathymetry & Whole study area. & $463 \mathrm{~m}$ side grid & $\begin{array}{l}\text { EMODNet Hydrography portal } \\
\text { (http://www.emodnet-hydrography.eu) }\end{array}$ \\
\hline Sediment & Study area except inner Loire. & $1 / 500000$ & $\begin{array}{l}\text { Bureau de Recherches Géologiques et Minières, } \\
\text { France }\end{array}$ \\
\hline & Inner Loire estuarine area. & & GIP Loire estuaire (pers. com.) \\
\hline Salinity & Whole study area. 1972-2011 & $\begin{array}{l}4 \mathrm{~km} \text { side grid, } \\
32 \text { layers }\end{array}$ & ECOMARS 3D (Lazure, 2009) \\
\hline Coastal exposure & Whole study area. 2002-2011 & $2 \mathrm{~km}$ side grid & PREVIMER (http://www.previmer.org/en/produits) \\
\hline \multicolumn{4}{|l|}{ Trawl Survey data } \\
\hline Vilaine & $\begin{array}{l}\text { 1984-1990; 1992; 1993; 1996; } \\
\text { 1997; 2000-2005; 2008-2010 }\end{array}$ & 740 hauls & IFREMER; IRSTEA \\
\hline Loire & $\begin{array}{l}1980 ; 1982-1984 ; 1986 ; 1997 ; \\
2000-2003 ; 2008 ; 2010\end{array}$ & 240 hauls & IFREMER; IRSTEA ; BIOLITTORAL \\
\hline Bourgneuf & $1981 ; 1982 ; 1997 ; 2000-2003 ; 2008$ & 98 hauls & IFREMER \\
\hline Pertuis Breton & $1986 ; 1987 ; 1996 ; 2000-2003$ & 140 hauls & IFREMER \\
\hline Pertuis d'Antioche & $1986 ; 1987 ; 1996 ; 2000-2003$ & 169 hauls & IFREMER \\
\hline Gironde & $\begin{array}{l}\text { 1996; 1997; 2000-2003; 2005; } \\
\text { 2009-2011 }\end{array}$ & 256 hauls & IFREMER ; IRSTEA \\
\hline $\begin{array}{l}\text { All sectors } \\
\text { combined }\end{array}$ & $\begin{array}{l}\text { 1980-1990; 1992; 1993; 1996; } \\
\text { 1997;2000-2005; 2008; 2009; 2010; } \\
2011\end{array}$ & 1643 hauls & \\
\hline
\end{tabular}


Table 2: Analysis of deviances of Generalized Linear Models for the 3 species a) S. solea

\begin{tabular}{|c|c|c|c|c|c|c|c|c|}
\hline \multirow[t]{2}{*}{ Model } & \multicolumn{4}{|c|}{ Binomial } & \multicolumn{4}{|c|}{ Gaussian on log (positive densities) } \\
\hline & $\overline{\mathrm{DoF}}$ & Deviance & $\operatorname{Pr}(\mathrm{Chi})$ & AIC & $\overline{\mathrm{DoF}}$ & Deviance & $\operatorname{Pr}(\mathrm{Chi})$ & $\overline{\mathrm{AIC}}$ \\
\hline Null & 1642 & 2235 & & 2237 & 953 & \multicolumn{2}{|l|}{2694} & 3702 \\
\hline +Salinity & 1640 & 2211 & $6.57 \mathrm{E}-06$ & 2217 & 951 & 2588 & $3.08 \mathrm{E}-12$ & 3667 \\
\hline+ Sediment & 1638 & 2140 & $3.91 \mathrm{E}-16$ & 2150 & 949 & 2539 & 5.34E-06 & 3653 \\
\hline +Bathymetry & 1635 & 1968 & $<2.2 \mathrm{E}-16$ & 1984 & 946 & 2317 & $<2.2 \mathrm{E}-16$ & 3572 \\
\hline +Mean wave & 1633 & 1932 & $1.58 \mathrm{E}-08$ & 1952 & 944 & 2243 & 8.89E-09 & 3545 \\
\hline $\begin{array}{c}\text { +Geographic } \\
\text { sector }\end{array}$ & 1628 & 1863 & $1.81 \mathrm{E}-13$ & 1893 & 939 & 2116 & $2.62 \mathrm{E}-12$ & 3500 \\
\hline+ Year & 1604 & 1758 & $4.49 \mathrm{E}-12$ & 1836 & 915 & \multirow[t]{2}{*}{1832} & $<2.2 \mathrm{E}-16$ & 3410 \\
\hline \multicolumn{5}{|c|}{$\Sigma$ explained deviance $(\%) \quad 21$} & \multicolumn{3}{|c|}{32} & \\
\hline \multicolumn{9}{|l|}{ b) P.platessa } \\
\hline \multirow[t]{2}{*}{ Model } & \multicolumn{4}{|c|}{ Binomial } & \multicolumn{4}{|c|}{ Gaussian on log (positive densities) } \\
\hline & DoF & Deviance & $\operatorname{Pr}(\mathrm{Chi})$ & $\mathrm{AIC}$ & DoF & Deviance & $\operatorname{Pr}(\mathrm{Chi})$ & AIC \\
\hline Null & 1386 & 1367 & & 1470 & 269 & \multicolumn{2}{|l|}{536} & 95 \\
\hline +Salinity & 1384 & 1303 & $1.16 \mathrm{E}-14$ & 1425 & 267 & 520 & $1.84 \mathrm{E}-04$ & 951 \\
\hline +Sediment & 1382 & 1251 & $3.93 \mathrm{E}-12$ & 1346 & 265 & 487 & $1.24 \mathrm{E}-08$ & 938 \\
\hline +Bathymetry & 1379 & \multirow[t]{2}{*}{1042} & $<2.2 \mathrm{E}-16$ & 1135 & 262 & 417 & $<2.2 \mathrm{E}-16$ & 902 \\
\hline +Mean wave & & & & & 260 & 373 & $3.65 \mathrm{E}-11$ & 876 \\
\hline $\begin{array}{c}\text { +Geographic } \\
\text { sector* }\end{array}$ & 1375 & 941 & $<2.2 \mathrm{E}-16$ & 967 & 256 & 350 & $3.27 \mathrm{E}-05$ & 866 \\
\hline+ Year & 1352 & 750 & $<2.2 \mathrm{E}-16$ & 824 & 235 & 214 & $<2.2 \mathrm{E}-16$ & 77 \\
\hline
\end{tabular}

*there is no P. platessa in the Gironde sector, removed from the model for this species

c) D. cuneata

\begin{tabular}{|c|c|c|c|c|c|c|c|c|}
\hline \multirow[t]{2}{*}{$\overline{\text { Model }}$} & \multicolumn{4}{|c|}{ Binomial } & \multicolumn{4}{|c|}{ Gaussian on log (positive densities) } \\
\hline & $\overline{\mathrm{DoF}}$ & Deviance & $\operatorname{Pr}(\mathrm{Chi})$ & AIC & $\overline{\mathrm{DoF}}$ & Deviance & $\operatorname{Pr}(\mathrm{Chi})$ & $\overline{\mathrm{AIC}}$ \\
\hline Null & 1642 & 1213 & & 1215 & 198 & 391 & & 703 \\
\hline +Salinity & 1640 & 1195 & $1.42 \mathrm{E}-04$ & 1201 & 196 & 369 & $9.36 \mathrm{E}-04$ & 696 \\
\hline +Sediment & 1638 & 1170 & $2.94 \mathrm{E}-06$ & 1180 & 194 & 350 & $2.61 \mathrm{E}-03$ & 689 \\
\hline $\begin{array}{l}\text { +Bathymetry } \\
\text { +Mean wave }\end{array}$ & 1635 & 1149 & $1.35 \mathrm{E}-04$ & 1165 & 191 & 335 & $1.81 \mathrm{E}-02$ & 686 \\
\hline $\begin{array}{c}+ \text { Geographic } \\
\text { sector }\end{array}$ & 1630 & 1105 & $1.76 \mathrm{E}-08$ & 1131 & & & & \\
\hline+ Year & 1606 & 945 & $<2.2 \mathrm{E}-16$ & 1019 & 168 & 273 & $8.46 \mathrm{E}-04$ & 678 \\
\hline \multicolumn{5}{|c|}{$\Sigma$ explained deviance $(\%)$} & \multicolumn{4}{|c|}{30} \\
\hline
\end{tabular}


Click here to download Table(s): Table 3.xlsx

\begin{tabular}{|c|c|c|c|c|}
\hline \multirow[b]{2}{*}{ Espèces } & \multicolumn{2}{|c|}{ AUC } & \multicolumn{2}{|c|}{$\mathrm{r}^{2}$} \\
\hline & Calib.* & Valid.** & Calib. & Valid. \\
\hline$\overline{\text { S. solea }}$ & 0.81 & 0.76 & 0.34 & 0.24 \\
\hline P. platessa & 0.91 & 0.88 & 0.61 & 0.51 \\
\hline D. cuneata & 0.81 & 0.73 & 0.32 & 0.25 \\
\hline
\end{tabular}

* calibration and ** validation data sets 
Click here to download Table(s): Table 4.xlsx

Table 4: Relative contribution and area by class of habitat factor under mean estuarine conditions

\begin{tabular}{|c|c|c|c|c|c|c|c|}
\hline \multirow[b]{2}{*}{ Factor } & \multirow{2}{*}{$\begin{array}{l}\text { Conditions } \\
\text { Class }\end{array}$} & \multicolumn{2}{|c|}{ S. solea } & \multicolumn{2}{|c|}{ P. platessa } & \multicolumn{2}{|c|}{ D. cuneata } \\
\hline & & Contr. (\%) & Area (\%) & Contr. (\%) & Area (\%) & Contr. (\%) & Area (\%) \\
\hline \multirow{3}{*}{ Salinity } & $>32$ & 56 & 51 & 15 & 41 & 31 & $\overline{51}$ \\
\hline & ] $30 ; 32$ ] & 24 & 29 & 38 & 39 & 35 & 29 \\
\hline & $<30$ & 20 & 21 & 47 & 20 & 34 & 21 \\
\hline \multirow{3}{*}{ Sediment } & Mud & 76 & 48 & 78 & 56 & 39 & 48 \\
\hline & Fine sand & 19 & 32 & 10 & 13 & 56 & 32 \\
\hline & Coarse sand & 6 & 19 & 12 & 31 & 6 & 19 \\
\hline \multirow{4}{*}{ Bathymetry } & $>-5$ & 78 & 23 & 81 & 35 & 38 & 23 \\
\hline & ]$-10 ;-5$ ] & 11 & 18 & 13 & 17 & 17 & 18 \\
\hline & ] $-20 ;-10$ ] & 8 & 23 & 6 & 26 & 35 & 23 \\
\hline & ] $-36 ;-20$ ] & 3 & 36 & 0 & 22 & 10 & 36 \\
\hline \multirow{3}{*}{$\begin{array}{l}\text { Wave } \\
\text { height }\end{array}$} & $<0.3$ & 68 & 19 & 44 & 22 & 31 & 19 \\
\hline & ] $0.3 ; 0.5$ ] & 15 & 8 & 20 & 17 & 7 & 8 \\
\hline & $>0.5$ & 17 & 73 & 35 & 61 & 62 & 73 \\
\hline \multirow{6}{*}{$\begin{array}{c}\text { Geographic } \\
\text { sector }\end{array}$} & Vilaine & 5 & 10 & 55 & $\overline{22}$ & 4 & 10 \\
\hline & Loire & 6 & 15 & 17 & 32 & 2 & 15 \\
\hline & Bourgneuf & 13 & 6 & 13 & 12 & 7 & 6 \\
\hline & Pertuis Breton & 15 & 7 & 9 & 15 & 10 & 7 \\
\hline & Pertuis Antioche & 44 & 9 & 7 & 19 & 9 & 9 \\
\hline & Gironde & 17 & 52 & $*$ & & 69 & 52 \\
\hline
\end{tabular}

* as there is no P. platessa in the Gironde estuary, this sector has been removed; contributions and surface were calculated on the 5 northern sectors 
Figure legends

Fig. 1: Map of the study area showing the six investigated sectors and the trawl hauls locations (dots). In the upper right corner: general location of the study site in Western Europe.

Fig. 2: Validation of the model for S. solea. ROC curve on train (a) and test (b) data for presence. (Area stands for the AUC index); Observed log-transformed positive densities versus predicted logtransformed positive densities for calibration (c) and validation (d) data.

Fig. 3: Mean effects (0-group density of each modality over mean density of whole data, cf Eq. (7)) of the different habitat factors on the 0-group densities of the three flatfish species. Abbreviations for sediment: $\mathrm{M}=\mathrm{Mud}, \mathrm{FS}=$ Fine Sand, $\mathrm{CS}=$ Coarse Sand and Gravel, $\mathrm{R}=$ Rock. Abbreviations for sector: V=Vilaine, $\mathrm{L}=$ Loire, $\mathrm{B}=$ Bourgneuf, $\mathrm{PB}=$ Pertuis Breton, $\mathrm{PA}=$ Pertuis d'Antioche, $\mathrm{G}=$ Gironde.

Fig. 4: Year mean effects 0 -group density of each year over mean density of whole time series, cf Eq. (7) ) for the three flatfish species.

Fig. 5: Density map for $S$. solea (top left), $P$. platessa (top right) and $D$. cuneata (bottom left) and sum of the 3 species (bottom right) under mean estuarine conditions. 


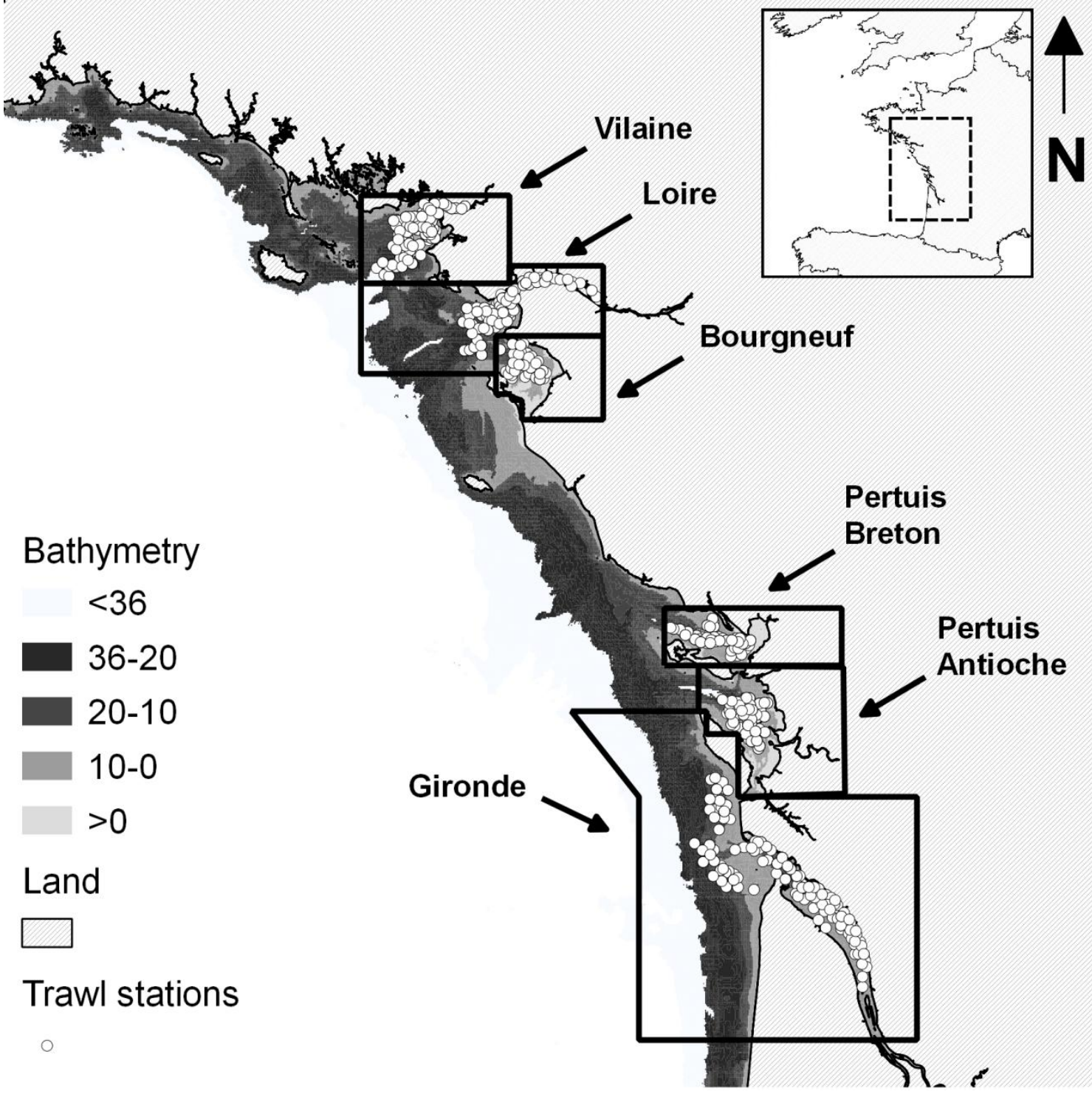


a)

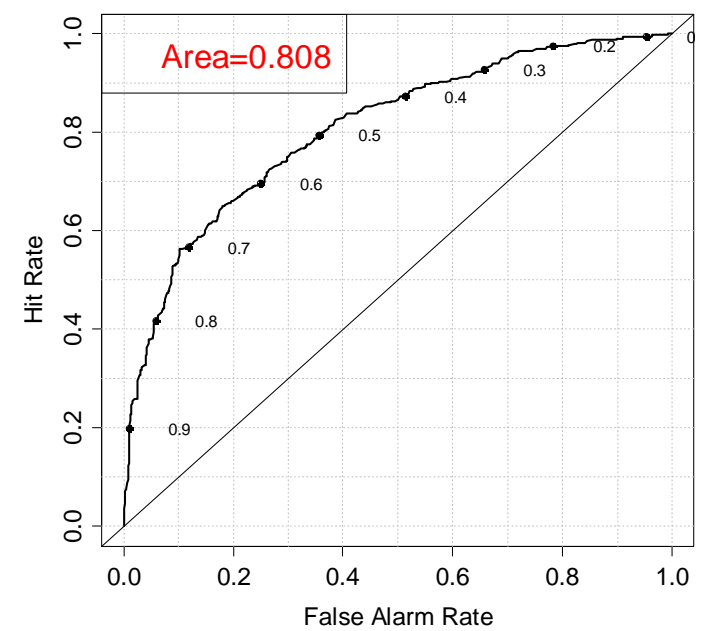

Train dataset - Log(positive density)

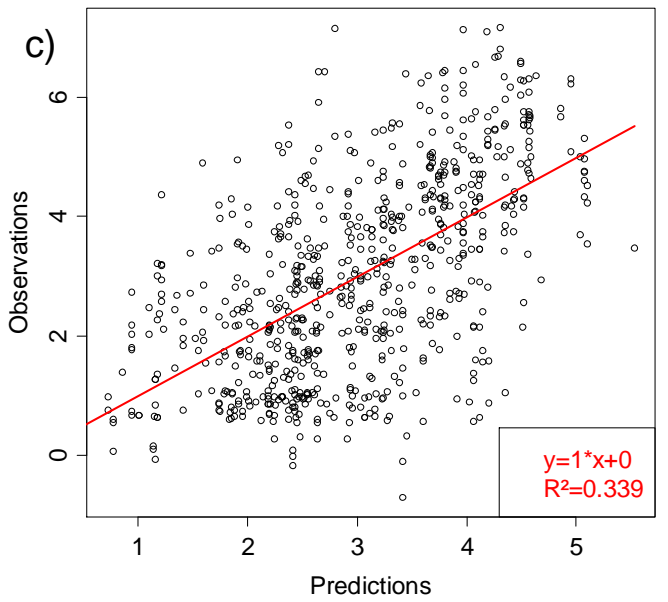

b) ROC Curve - Test dataset

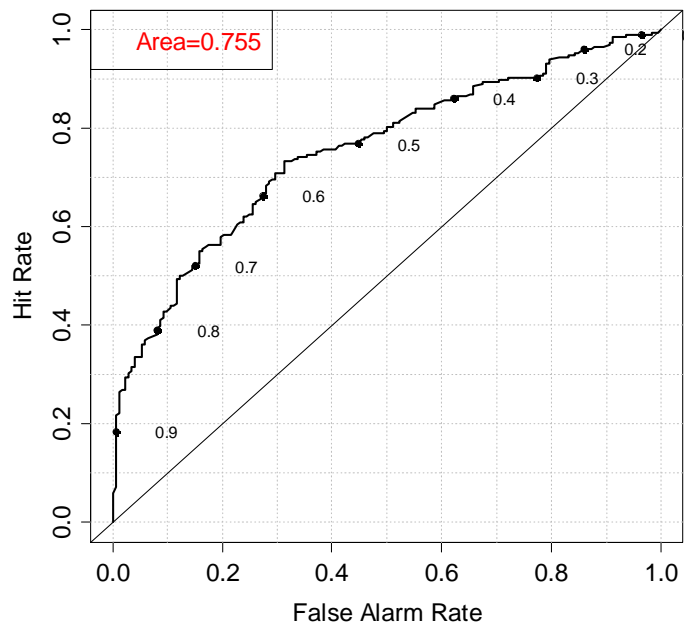

Test dataset - Log(positive density)

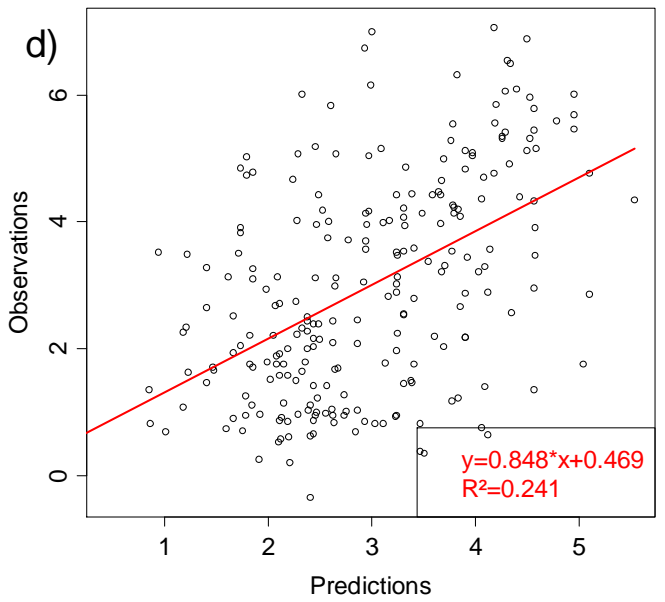




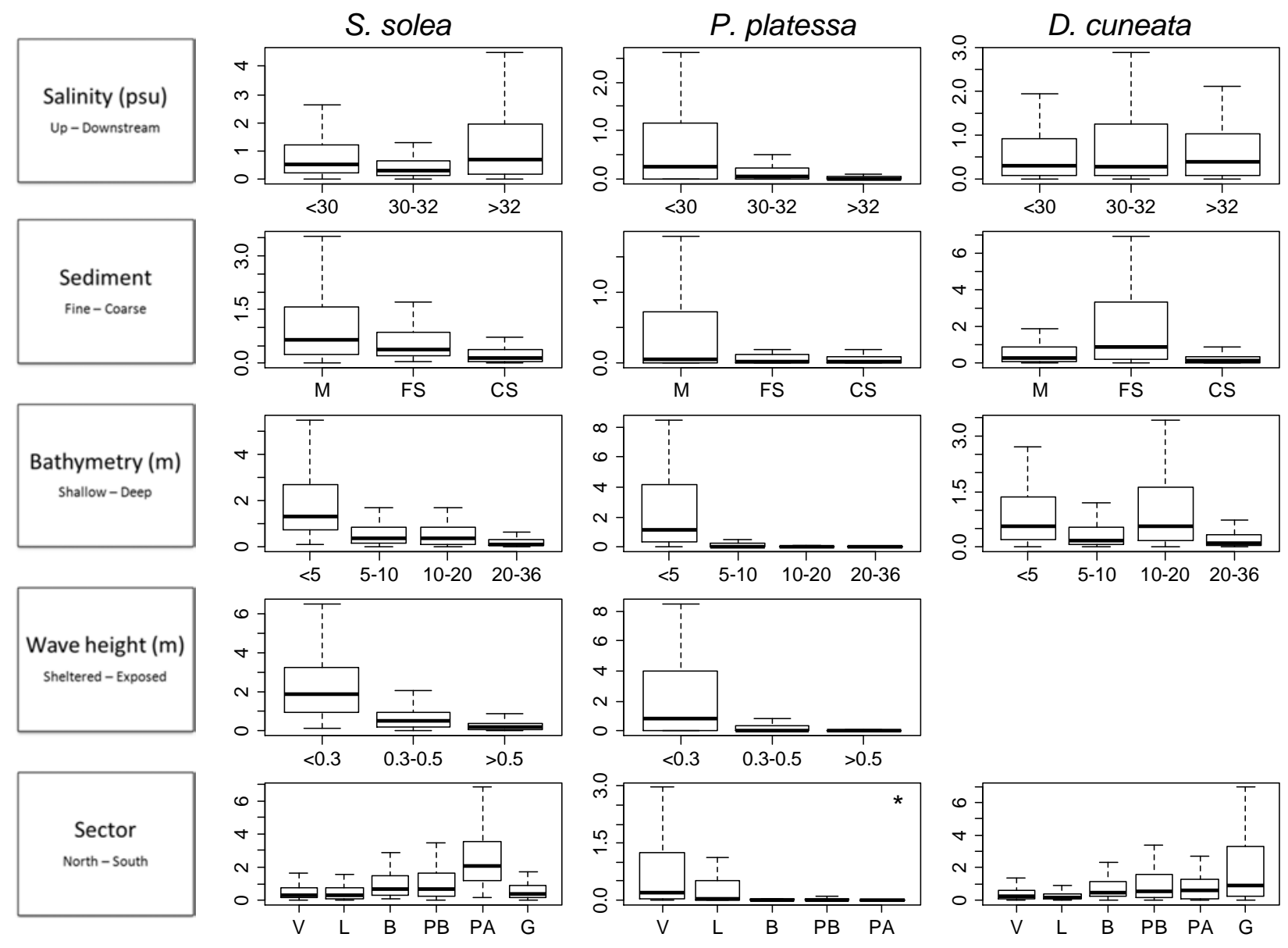

${ }^{*}$ there is no $P$. platessa in the Gironde sector, removed of the model for this species 
S. solea

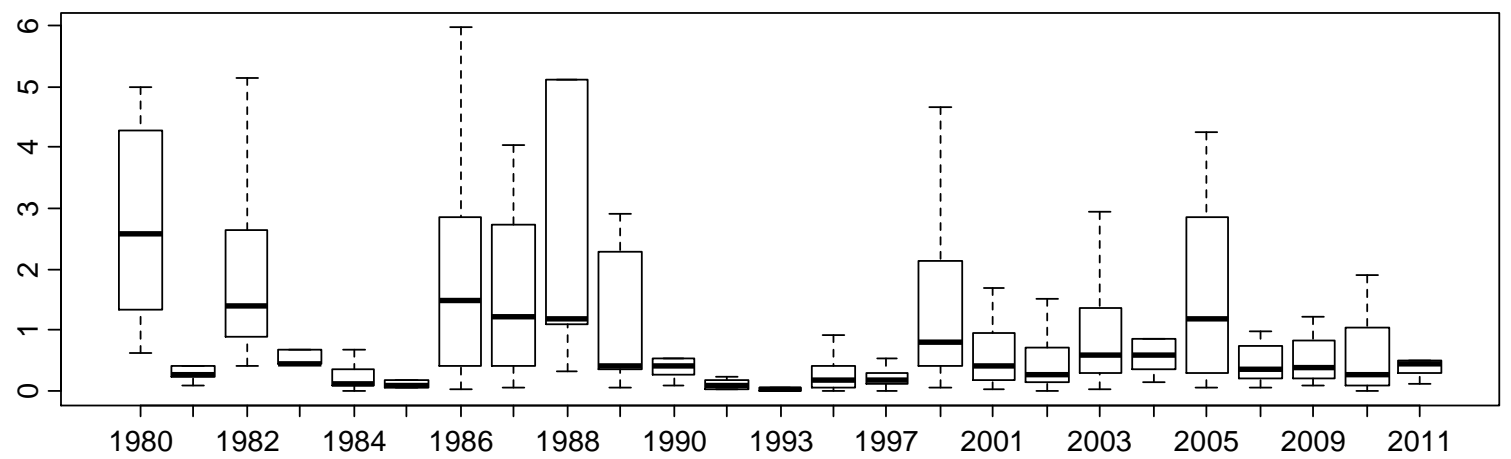

P. platessa

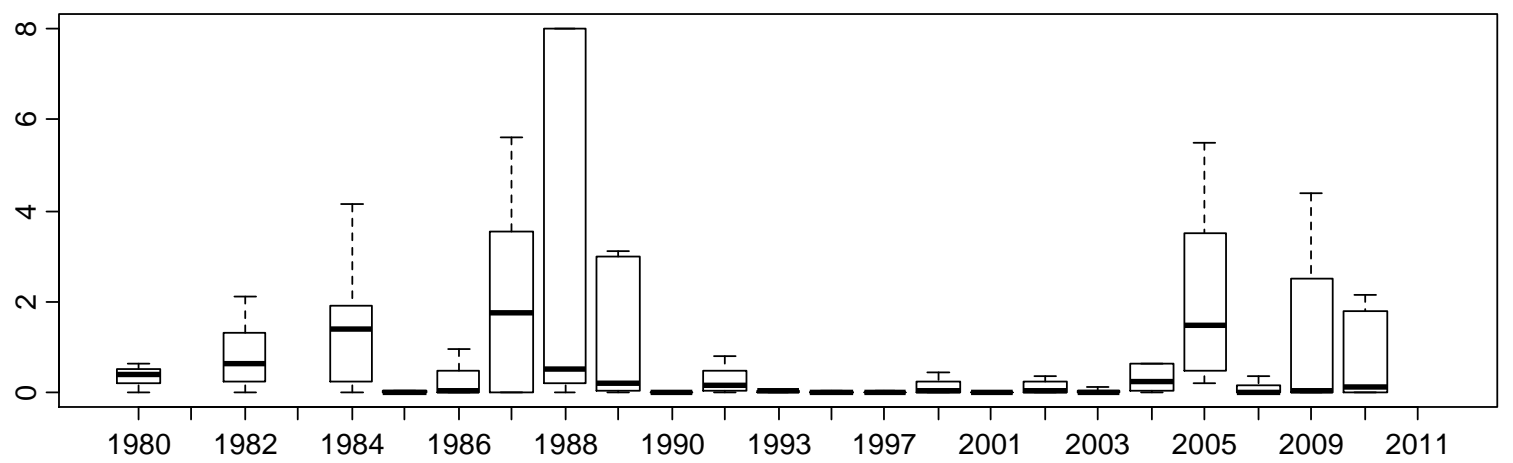

D. cuneata

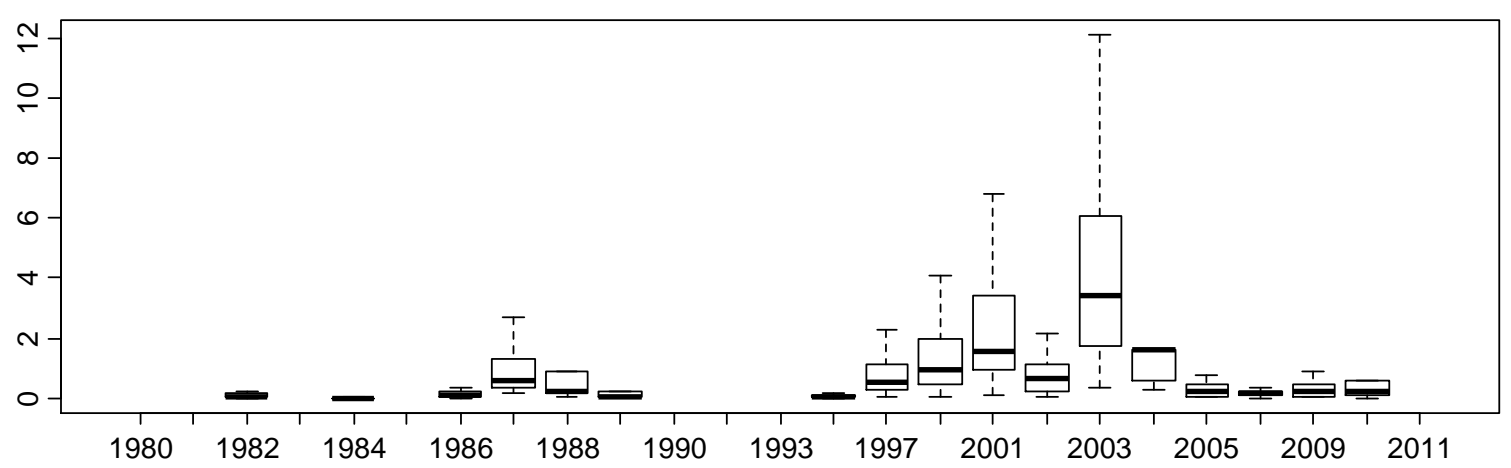


Figure 5



